KURZ GEMELDET

Allergy News

\section{Die Chlor-Hypothese}

$\mathrm{B}$ elgische Umweltmediziner konnten eine klare Dosis-Wirkungsbeziehung zwischen dem Aufenthalt in Hallenbädern mit gechlortem Wasser und der Permeabilität des Atemwegsepithels bei Kindern feststellen. Bereits eine einstündige Exposition gegenüber Stickstofftrichlorid in der Hallenbadluft - die Kinder mussten gar nicht im Wasser sein - reichte aus, um die Serumkonzentrationen der Surfactant-assoziierten Proteine A und B signifikant zu erhöhen. Mehr noch, bei den 266 Probanden korrelierte die Häufigkeit des Schwimmbadbesuchs positiv mit dem

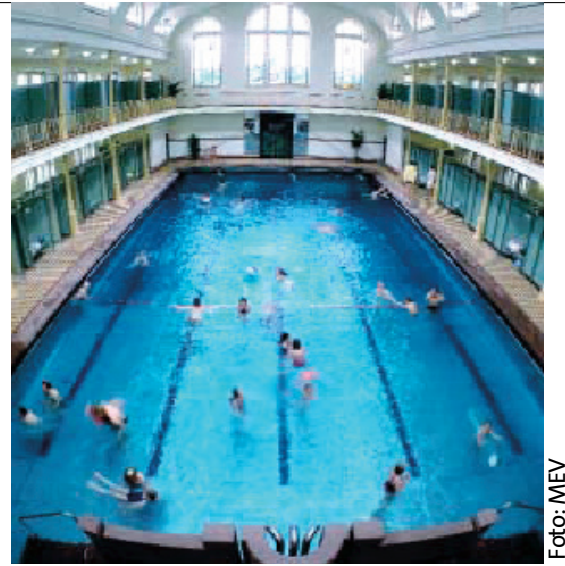

Asthmarisiko. Die Autoren bieten ihre Beobachtung als eine Erklärung für die in den westlichen Industrieländern weiter steigende Asthmaprävalenz an.

Bernard A et al. Occup Environ Med 2003; 6o: 385-94

\section{Kein Zertifikat für Heilpraktiker}

\begin{abstract}
_ s stellt keine unzulässige Diskriminierung eines Heilpraktikers dar, wenn ein Verein, der eine Weiterbildung zum so genannten Asthmatrainer anbietet und dafür auch Zertifikate ausstellt, aus grundsätzlichen Erwägungen Heilpraktikern das Zertifikat nicht erteilt, sondern dieses Heilberufen mit einem staatlichen Abschluss im Sinne der Schulmedizin vorbehält.

$j l p$
\end{abstract}

Oberlandesgericht Oldenburg, Az. $8 \mathrm{U}$ 189/01

\section{Ei in der Luft}

tivität nachzuweisen. Als Verursacher konnten jedoch keine Proteine aus der Bet-v1-Familie identifiziert werden, vielmehr war in einem Fall ein Birkenprotein mit $51 \mathrm{kDa}$ für die Kreuzreaktivität verantwortlich. Trotz der noch etwas dünnen Datenlage raten die Autoren dazu, Schikoree in die Liste der Nahrungsmittel aufzunehmen, die bei Birkenpollenallergie zu oralen allergischen Symptomen führen.

Cadot $\mathbf{P}$ et al. Int Arch Allergy Immunol

2003; 131: 19-24 Verfügung, um eine direkte Kreuzreak-

\section{Der Schlips macht's nicht}

Z wölf Ärzte eines australischen Lehrkrankenhauses trieben eifrig Maskerade im Dienst der Wissenschaft. Im Monatsabstand wechselten sie ihr Outfit, mutierten vom konservativen Krawatten- zum lässigen Jeansträger mit Hawaiihemd, verzichteten dann auf den weißen Kittel und präsentierten sich ihren Patienten schlussendlich sogar mit Nasenring. Die Patienten wurden nach der Behandlung dann befragt, ob sie den jeweiligen Kollegen für vertrauenswürdig hielten. Den größten Vertrauensverlust bewirkte der

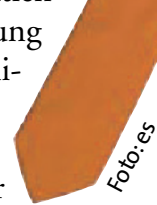

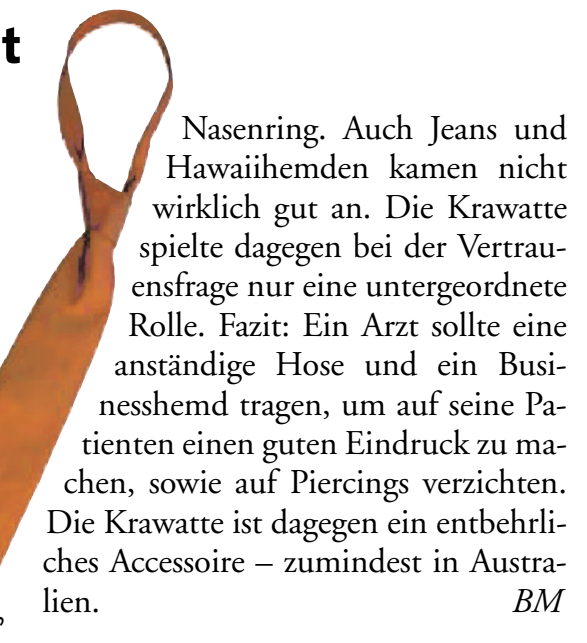

Dobson R. BMJ 2003; 326: 1231

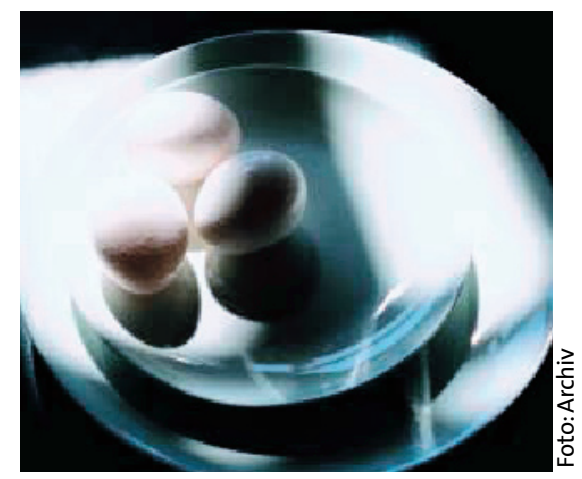

ei der Verarbeitung von Flüssigei in Bäckereien oder Konditoreien können offenbar so viele Hühnereiweißbestandteile in die Luft gelangen, dass das so entstandene Aerosol bei entsprechender Sensibilisierung Asthmaanfälle auslöst. Allergologen aus Madrid dokumentierten die Fälle von vier Bäckern, die auf die inhalative Provokation mit Lysozymaerosol asthmatisch reagierten. Bei zweien der Probanden führte auch die Provokation mit Ovalbumin, bei einem mit Ovomukoid zu einem asthmatischen Anfall. Bei allen vier Bäckern ließ sich außerdem spezifisches IgE gegen Hühnereiweiß nachweisen, ebenso war der Pricktest mit Hühnereiweiß und mit Lysozym positiv.

Escudero C et al. Allergy 2003; 58: 616-20 